\title{
VEGFR3 and Milroy Disease: Novel Mutations, a Review of Published Variants and Database Update
}

Kristiana Gordon ${ }^{1}$, Sarah L. Spiden ${ }^{2}$, Fiona C. Connell ${ }^{3}$, Glen Brice ${ }^{4}$, Sally Cottrell ${ }^{2}$, John Short $^{2}$, Rohan Taylor ${ }^{2}$, Steve Jeffery ${ }^{5}$, Peter S. Mortimer ${ }^{1}$, Sahar Mansour ${ }^{4}$, Pia Ostergaard ${ }^{5}$

1 Department of Cardiac and Vascular Sciences, St George's University of London, London SW17 ORE, UK.

2 SW Thames Molecular Genetics Diagnostics Laboratory, St. George's NHS Trust, London SW17 0QT, UK.

3 Clinical Genetics, Guy's and St Thomas' NHS Foundation Trust, Guy's Hospital, London SE1 9RT, UK.

${ }^{4}$ SW Thames Regional Genetics Service, St. George's University of London, London SW17 ORE, UK.

${ }^{5}$ Medical Genetics, Biomedical Sciences, St George's University of London, London SW17 ORE, UK.

Grant numbers: British Heart Foundation Clinical Research Training Fellowship

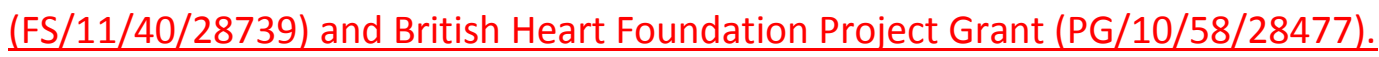

ABSTRACT: Milroy disease (MD) is an autosomal dominantly inherited primary lymphoedema. In 1998, the gene locus for MD was mapped to $5 q 35.3$ and mutations in VEGFR3 (FLT4) were identified as being responsible for the majority of MD cases. Several reports have since been published detailing pathogenic VEGFR3 mutations. To date, a total 
of 58 different variants in VEGFR3, 20 of which are unpublished, have been observed in 95 families with MD. A review of published mutations is presented in this update. Furthermore, the unpublished variants are presented including clinical data. Comparison of clinical features in patients and their families with the same mutations reveals incomplete penetrance and variable expression, making genotype-phenotype correlations difficult. Most mutations are missense, but a few deletions and one splicing variant have also been reported. Several animal models have confirmed the role of VEGFR3 in lymphangiogenesis and studies show mutant VEGFR3 receptors are not phosphorylated. Here, a MD patient with the same p.Ile1053Phe change as seen in the Chy mouse is presented for the first time. This finding confirms that this mouse lineage is an excellent model for MD. All the data reviewed here has been submitted to a database based on the Leiden Open (source) Variation Database (LOVD) and is accessible online at www.lovd.nl/flt4.

KEY WORDS: Primary Lymphoedema; Milroy Disease; VEGFR3; FLT4; Chy mouse; LOVD database;

\section{Background}

Milroy disease (MD; hereditary lymphoedema type I; MIM 153100) is a congenital onset, primary lymphoedema and is caused by dysfunction of the lymphatic system. It was first described by William Milroy in 1892. Connell et al. [2010] and Brice et al. [2005] give the most current and complete descriptions of Milroy disease, the latter also gives a comprehensive overview of the history of primary lymphoedema. The oedema in Milroy disease is painless and chronic. A typical Milroy patient presents with lymphoedema at birth 
and the swelling is usually bilateral and confined to the dorsum of the foot. Swelling can extend beyond the ankle and up to the knee. Deep skin creases may be seen on the toes. The skin often has a brawny texture and hyperkeratosis is a common feature. Often the patients have large calibre great saphenous veins but show no cutaneous signs of venous disease. Other associated features include small dysplastic, upslanting toe nails, papillomatosis of the toes, recurrent cellulitis and hydrocoeles in male patients. Investigation with lymphoscintigraphy demonstrates little or no uptake by initial, peripheral lymphatics in the foot. A typical Milroy patient will show no dysmorphic features, no constitutional symptoms or other clinical manifestations.

The swelling in MD completely regresses in only $10 \%$ of patients who present at birth [Brice et al., 2005]. There is marked inter- and intra-familial variation in the degree of symptoms, ranging from toe swelling to swelling of entire below-knee region. Asymptomatic, obligate carriers, who show no signs of MD, have been reported, and many pedigrees show reduced penetrance at around 80-84\% [Ferrell et al., 1998; Evans et al., 1999]. Although most patients are diagnosed with swelling from birth, some family members have been reported to develop swelling later in life [Brice et al., 2005]. Occasionally, MD has been diagnosed prenatally as in utero pleural effusions, hydrops fetalis [Daniel-Spiegel et al., 2005; Ghalamkarpour et al., 2006; Ghalamkarpour et al., 2009a] or swelling of the dorsum of the feet seen by ultrasound in the third trimester. Hydrops fetalis can result in intrauterine death or may regress leaving swelling confined to the dorsum of the feet.

$\mathrm{MD}$ is relatively rare but there are no reliable incidence figures. MD is inherited in an autosomal dominant manner. A family history is not essential for the diagnosis of MD; de 
novo cases have been reported [Ghalamkarpour et al., 2006; Carver et al., 2007;

Ghalamkarpour et al., 2009a]. Interestingly, there is one recessive case in the literature describing a MD patient with homozygous mutations in VEGFR3 [Ghalamkarpour et al., 2009b]. This case will be discussed later in the paper.

Several groups independently mapped MD to chromosome 5q35. [Ferrell et al., 1998; Witte et al., 1998; Evans et al., 1999]. A gene in this region, VEGFR3, Vascular Endothelial Growth Factor Receptor 3, (also known as FLT4), was found to be causative for some cases of MD [Ferrell et al., 1998; Irrthum et al., 2000; Karkkainen et al., 2000]. Studies showed that mutations within the tyrosine kinase domains of the receptor were sufficient to reduce tyrosine kinase activity and thereby affecting lymphatic development [Karkkainen et al., 2000]. The same paper suggested it was likely that the mutant receptor remained longer on the cell surface than the wild type, thus, presumably, decreasing kinase activity. VEGFR3 is recognised as a major determinant in the development and growth of lymphatic vessels and the mature protein is a tyrosine kinase receptor for vascular endothelial growth factors $C$ and D [Joukov et al., 1996; Yamada et al., 1997]. VEGFR3 (NM_182925, MIM gene 136352) has 31 exons of which 30a and 30b are alternatively spliced. The transcripts encode a protein with an extracellular domain containing seven immunoglobulin-like repeat domains, a trans-membrane region and two intracellular tyrosine kinase domains (TK1 and TK2) [Pajusola et al., 1992; Iljin et al., 2001]. The gene is expressed in all vessels during embryogenesis but in adult tissue its expression is limited to the lymphatic endothelium [Kaipanen et al., 1995]. 
Various reports have described different mutations in VEGFR3 in probands and families with MD [Evans et al., 2003; Mizuno et al., 2005; Ghalamkarpour et al., 2006; Spiegel et al., 2006; Butler et al., 2007; Carver et al., 2007; Yu et al., 2007; Futatani et al., 2008; Connell et al., 2009; Ghalamkarpour et al., 2009a and 2009b; Verstraeten et al., 2009; Kitsiou-Tzeli et al., 2010]. Causative mutations have been described in the kinase domains alone, but only a few of the papers looked at the whole gene [Evans et al., 2003; Connell et al., 2009]. VEGFR3 mutations do not account for all cases of $\mathrm{MD}$, and some reports have suggested that there may be considerable genetic heterogeneity [Holberg et al., 2001]. Connell et al. [2009] reported that with rigorous phenotyping about $70 \%$ of $M D$ cases were positive for a VEGFR3 mutation. In this review, we summarise all 38 VEGFR3 mutations published so far and present 20 new mutations, including one which is the same mutations found in the Chy mouse model. All variants (new and previously published) have been added to a web-based database and future reporters of VEGFR3 mutations are welcomed to include their findings within this database.

\section{Database}

Literature search in PubMed was performed to identify all known VEGFR3 mutations. In addition, St George's Hospital (SGH), London, UK has been offering VEGFR3 screening services since 2006 (www.southwestthamesgenetics.nhs.uk). Some of the mutations detected through this service have been previously published [Connell et al., 2009] but further mutations have been identified since this report, and they are presented below with a short summary of the clinical findings in these additional patients. All available information on mutations and mutation carriers has been transferred to the web-accessible Leiden Open Variation Database (LOVD) [Fokkema et al., 2005]. This database is included in 
the Human Genome Variation Society (HGSV) list of Locus Specific Databases. The database can be visited at www.lovd.nl/FLT4 and has been updated with data from the literature as well as unpublished variants identified in our diagnostic services. Furthermore, all scientists, clinicians and diagnostic services are encouraged to submit their variants to the database, using an online submission form. The identity of the submitter will be clearly acknowledged in the database. One of the major goals of the establishment of the VEGFR3 database is to collect information on variants in the gene together with the clinical findings of the MD patients in order to harmonize the clinical criteria for diagnosis.

\section{Summary of clinical findings in unpublished patients}

Forty-four mutations (of which 20 are unreported, novel mutations) in the VEGFR3 gene were identified in 43 patients by the SW Thames Molecular Genetics Diagnostic Laboratory at SGH between 2009 and 2011. The majority of patients (27/43) were from our Primary Lymphoedema Clinic. The remainder were referred from other European countries for analysis, but accompanying clinical information tended to be sparse. The major clinical findings associated with mutations are provided in Table 1.

Although expression was variable there was no obvious difference between males and females. Eighteen patients were male, 21 were female and four cases had no gender stated on the referral form. Data relating to the onset and distribution of lymphoedema were available for 27 patients. All 27 patients had congenital lymphoedema, i.e. onset within the first year of life. The swelling was more likely to be bilateral (24/27 patients, $89 \%)$ rather than unilateral ( $3 / 27$ patients, $11 \%)$. The majority of patients had lymphoedema localised to 
the feet ( $17 / 27$ patients, $63 \%)$, but a minority had swelling of feet and ankles (5/27 patients, $18 \%)$ or up to the knees (5/27 patients, $18 \%)$.

Eleven males with VEGFR3 mutations were examined for the presence of hydroceles. Of these, three $(27 \%)$ were noted to have hydroceles. Several incidences $(n=6)$ of hydroceles have been reported in extended family members of affected female probands recruited from SGH. These findings are similar to those found by Brice et al. [2005], where hydroceles were detected in $37 \%$ of males with MD.

Hydrops fetalis (defined as generalized subcutaneous edema with an effusion in at least 1 body cavity) is a rare feature of MD and we only have one confirmed case within our cohort. One female patient (Ped 7) with a VEGFR3 mutation had a history of recurrent miscarriages: one due to hydrops fetalis (fetal DNA analysis confirmed a VEGFR3 mutation) and a second due to an unexplained intrauterine death (fetal DNA not analysed). During her third pregnancy the fetus developed pleural effusions but these spontaneously resolved (VEGFR3 analysis on CVS sample confirmed the mutation). Another unusual case is that of a boy (Ped 37) born prematurely at 32 weeks gestation with congenital generalised skin oedema but no ascites or pleural effusions. The unexplained swelling lasted two days before spontaneously resolving. However, he developed further swelling of just his feet within a couple of days, and the swelling (typical of MD) persists into childhood. Lastly, epicanthic folds were observed in 3 of our patients $(3 / 27,11 \%)$. We suspect that this reflects a period of in-utero subcutaneous oedema rather than "full-blown" hydrops fetalis, presumably as part of the MD phenotype. 
Lymphoscintigraphy results were available for eight of the 43 patients. Lymphoscintigraphy is not performed routinely in patients with MD as the results do not alter management in the majority of cases. In those patients undergoing lymphoscintigraphy, six of the eight (75\%) results were typical of $\mathrm{MD}$, i.e. demonstrating a functional aplasia of peripheral lymphatics with minimal or no evidence of tracer uptake into the main lymphatic tracts or inguinal lymph nodes after two hours of imaging. Two female patients had lymphoscintigraphy results not in keeping with MD. One patient with bilateral lymphoedema (right foot more swollen than the left) had the typical MD lymphoscintigraphy findings of a functional aplasia of lymphatics within the right leg, but appeared to have functional (albeit sluggish) main lymphatic tracts in the left leg. The other patient with atypical lymphoscintigraphy findings had symmetrical lymphoedema of both feet. However, her scans demonstrated functioning main lymphatics in both lower limbs. The vessels were tortuous and varicose on the images, and appeared to cause a reflux of lymph in the lower portion of the legs in a pattern similar to that seen in patients with Lymphoedema-Distichiasis syndrome [Brice et al., 2002]. The reasons for this atypical pattern on lymphoscintigraphy have yet to be determined.

Venous duplex imaging was undertaken in five of the 43 patients. All five (age range: 8-44 years) had evidence of great saphenous vein incompetence. This is entirely consistent with published data [Mellor et al., 2010]. Although the majority of patients with VEGFR3 mutations did not undergo venous imaging, a significant number (16/25 patients that were examined, 64\%) were noted to have prominent veins on clinical examination of their lower limbs. 
In summary, our cohort of 43 patients with VEGFR3 mutations demonstrate clinical features recognised in patients with previously reported VEGFR3 mutations.

\section{Variants in the VEGFR3 gene}

Ninety-five MD patients (including the new ones described above) with an identified VEGFR3 mutation are registered in the FLT4-LOVD database (www.lovd.nl/FLT4). All base changes are predicted to be pathogenic based on their location in functional domains. Mutations are named according to HGVS nomenclature guidelines (www.HGVS.org), numbered with respect to the VEGFR3 gene reference sequence (NG_011536 covering VEGFR3 gene transcript NM_182925) and nomenclature of all mutations have been checked using Mutalyzer (www.LOVD.nl/mutalyzer/) [Wildeman et al., 2008].

Thirty-eight unique point mutations or small indels have been reported previously in the literature (Table 2) and this paper adds another 20 (Table 1 ) to the list of mutations identified in MD patients. Most reported mutations are missense $(n=54)$, but a splicing variant $(n=1)$ and deletions $(n=3)$ have also been observed. The majority of mutations have only been reported once, ten have been reported twice (see Fig. 1). The variants p.Gly933Arg and p.Arg1041GIn have been reported five times, and p.Phe1108del has been reported six times. All mutations are located in the tyrosine kinase domains 1 or 2 of the receptor (exons 17-20 and 22-26 respectively) (Fig. 1). Mutations in regulatory domains or intronic regions outside the sequence immediately flanking the exons have not been described, most likely because these regions of the gene are not routinely screened or have yet to be fully characterised. Furthermore, no mutations have to date been reported for 
exons outside the tyrosine kinase domain [Evans et al., 2003; Connell et al., 2009], but in some cases this could be due to ascertainment bias as only those domains were sequenced.

\section{Sporadic cases}

There are seven de novo mutations reported in the literature [Ghalamkarpour et al., 2006; Carver et al., 2007; Connell et al., 2009; Ghalamkarpour et al., 2009] and five of the 43 new cases reported here (Table 1) are confirmed de novo. These numbers may be an underestimate, as parental DNA is often not available for testing. For example, of the 43 cases in Table 1, parental DNA was not available for six of the cases to confirm possible inheritance.

\section{Splicing variant}

To date only one splice site mutation has been reported. It is a single nucleotide deletion at the splice donor site, IVS17+2delT. Subcloning of RT-PCR products showed that the majority of colonies had normal splicing products and only $14 \%$ had abnormal splice products. Abnormal splicing would result in a premature termination of the transcripts causing a loss of the majority of the TK1 and TK2 domains [Futatani et al., 2008], but it was speculated that, due to accelerated degradation of mutated mRNA by the mechanism of nonsensemediated decay, the proportion of aberrant splicing products was low. With a low percentage of abnormal product, most heterodimers in this patient consisted of predominantly normal VEGFR3, which could explain the relatively mild phenotype reported by Futatani et al. [2008]. 


\section{Deletions}

The three deletions reported to date, p.Met894del, p.Leu913del, p.Phe1108del, are all small deletions of three bases eliminating a codon. All residues are conserved across species and MutationTaster (http://www.mutationtaster.org/) [Schwarz et al., 2010] predicts all three deletions to be disease causing, but the exact significance of these deletions for the function of the receptor has not been investigated.

\section{Homozygous mutation}

A homozygous missense mutation, p.Ala855Thr, in the ATP binding domain of TK1 of VEGFR3 was found in an MD patient born to first-cousin parents [Ghalamkarpour et al., 2009b]. Interestingly, both parents were heterozygous but unaffected, and it was concluded that the p.Ala855Thr mutation is hypomorphic. Only the patient homozygous for this change has developed MD. In a heterozygous state the remaining function in the mutated protein added to the activity from the product of the wild type allele seems sufficient to maintain a normal phenotype. The partial loss of function in the p.Ala855Thr heterozygotes is not as severe as that seen for the other mutations described above.

\section{Compound heterozygous mutation?}

There has been one report of a compound heterozygote where neither of the parents were affected, but when expressing the two mutants in a cell line it was found that the maternal change p.Gly933Arg was hardly phosphorylated whereas the paternal change p.Asp1049Asn was phosphorylated to similar levels as wild type [Verstraeten et al., 2009]. The proband's half-sister via the mother was also diagnosed with MD. She was found to carry the p.Gly933Arg variant, which also has been reported in other patients previously [Evans et al., 
2003; Connell et al., 2009]. It was therefore concluded that the p.Asp1049Asn was probably a rare polymorphism (listed as RS56310180 in dbSNP with a heterozygosity frequency of $0.1 \%)$, and therefore this patient is not truly a compound heterozygote and the unaffected, obligate carrier mother is another example of how variable penetrance can be in MD.

\section{Double mutation?}

Interestingly, one of our patients (Ped 8 in Table 1) carries both a deletion (p.Met894del described above) and a missense variant (p.Arg1145Cys) in VEGFR3. She is clinically very similar to other MD patients. The proband's father also carries the two changes and has similar clinical signs. When the paternal grandparents were screened, only the grandmother was positive and only for the p.Arg1145Cys variant, the p.Met894del was not found in either grandparent. The grandmother was reported to have no oedema, but has not been seen in clinic for confirmation. From the information available it seems likely that p.Met894del mutation has arisen de novo in the proband's father on the same allele as the p.Arg1145Cys variant, with this haplotype being passed on to his daughter.

At present, we cannot tell if p.Met894del and p.Arg1145Cys are acting together. Deletions (see above) have been reported in other MD patients, so it is anticipated that the p.Met894del mutation alone is consistent with the clinical diagnosis of MD. The p.Arg1145Cys variant is predicted to be a polymorphism by Mutation Taster. In Alamut (www.interactive-biosoftware.com) the predictions are divergent as the variant is inferred to be non-pathogenic by AlignGVGD, whereas SIFT and Polyphen-2 forecast it to be deleterious and possible damaging. In addition, the p.Arg1145Cys change is two bases upstream of the acceptor site of exon 26 and it is predicted in Alamut that the $\mathrm{C}$ to $\mathrm{T}$ change 
at this position increases the efficiency of splicing. Hence, it is difficult to assess the significance of the p.Arg1145Cys variant on VEGFR3 function.

\section{Somatic mutation}

There is one report of a somatic mutation in VEGFR3, p.Pro954Ser, which sits in the kinase insert (exon 21) between the two tyrosine kinase domains. This somatic missense mutation was reported in one infantile haemangioma specimen and it was suggested that VEGFR3 is involved in haemangioma formation [Walter et al., 2002].

\section{Ethnic variation}

There are no numbers to be found in the literature on the ethnic variation of MD. When looking at the ethnicity reported in the LOVD database there are reports on African, Arabic, Asian, Caucasian, Chinese, Hispanic, and Japanese origin. The majority of cases are Caucasian, but that is presumably ascertainment bias, as most of the reports so far are from the UK.

\section{Biological Relevance}

The lymphatic system is a network of blind-ended capillaries, collecting vessels and lymphoid organs. Apart from maintenance of fluid homeostasis it is also important for immune surveillance and fat absorption. Interstitial proteins and water extravasated from blood capillaries are absorbed by lymphatic capillaries and moved along the lymphatic network by peristalsis of the collector lymph vessels, or by compression from surrounding skeletal muscles. Lymphoedema is characterised by swelling in the tissue caused by the 
accumulation of lymph fluid either due to damage, malformation or malfunction of the lymphatic system.

The lymphatic system develops through various steps and the process starts around embryonic week 6-7 in humans. Lymphangiogenesis is controlled by several key factors. Only the main aspects will be covered briefly here, focusing on the role of VEGFR3. More detailed information can be found in recent reviews on lymphangiogenesis [Tammela and Alitalo, 2010; Norrmen et al., 2011; Schulte-Mercker et al., 2011].

The VEGFR3 gene provides instructions for making a protein called vascular endothelial growth factor receptor 3 (VEGFR3), which regulates the development and maintenance of the lymphatic system. VEGFR3 is activated by two proteins called vascular endothelial growth factor C (VEGFC) and vascular endothelial growth factor D (VEGFD) [Joukov et al., 1996; Yamada et al., 1997] and can form homodimers with itself or heterodimers with VEGFR2. When VEGFC and VEGFD bind to VEGFR3, docking sites for downstream signalling proteins are produced, which regulate the proliferation, migration, and survival of lymphatic endothelial cells (LECS).

VEGFR3 has an important role in the development of the lymphatic vasculature. Initially, VEGFR3 is highly expressed in blood vasculature endothelial cells where it plays a role in vasculogenesis. No live-born Vegfr3-/- mice have been observed. Blocking of Vegfr3 leads to a less dense vascular network and a decrease in proliferation of LECs. This results in severe necrosis by embryonic day (E) 12.5 and death due to vascular defects in these homozygously mutated mice. [Dumont et al., 1998; Tammela et al., 2008]. 
The development of the lymphatic system starts after arterial and venous endothelial cells have differentiated. When lymphangiogenesis is initiated, VEGFR3 expression is downregulated in the blood vessels and is maintained in the venous system, particularly in a subpopulation of endothelial cells in the cardinal veins [Kaipanen et al., 1995; Tammela et al., 2008]. At the same time the transcription factor, SOX18, induces PROX1 expression in these cells and in the presence of VEGFC, LEC determination is initiated and migration and proliferation of LECs to form primary lymph sacs begins [Francois et al., 2008; Wigle et al., 2002]. Around E10 in mice, the Vegfr3 signals become restricted to LECs [Kaipanen et al., 1995; Dumont et al., 1998] and growth of the lymphatic system continues, driven by VEGFC and VEGFR3 [Makinen et al., 2001].

In contrast, VEGFD seems to be dispensable for lymphatic development in mice as Vegfd-/mice show no evidence of lymphoedema and the lymphatic system looks similar to that of the WT [Baldwin et al., 2005; Haiko et al., 2008]. A combined deletion of Vegfc and Vegfd in mice does not mirror the inactivation that was observed in the Vegfr3-/- mice as described above, which suggests that other factors can activate VEGFR3 [Haiko et al., 2008].

It is clear from mouse models that VEGFC and VEGFR3 are important for lymphatic development. For example, Vegfc-/- mouse embryos have no lymphatic vasculature and die. The LEC precursor cells in the cardinal vein start differentiating but fail to migrate and form primary lymph sacs. Notably, Vegfc+/- mice survive into adulthood but have severe lymphatic dysplasia [Karkkainen et al., 2004]. As mentioned above, no live born Vegfr3-/mice have been observed, but interestingly Vegfr $3+/$ - mice are phenotypically normal 
[Dumont et al., 1998]. In contrast, adult Chy mice have chronic lymphoedema of the limbs, indicating defects in the lymphatic system. Chy mice have a heterozygous germline Vegfr3 mutation resulting in a p.lle1053Phe substitution [Karkkainen et al., 2001]. This mouse line is characterised by hypoplasia of cutaneous lymph capillaries and defective lymph vessels in the skin. Postnatally, $10 \%$ of pups were observed to have chylous fluid in the abdomen, which spontaneously resorbed. The p.lle1053Phe mutation sits in the highly conserved tyrosine kinase domain of the VEGFR3 receptor. Wild type mice show normal phosphorylation of the VEGFR3 receptor, whereas the Chy mice with the p.lle1053Phe substitution had impaired kinase activity in a similar manner to the Vegfc+/- mice [Karkkainen et al., 2004; Dellinger et al., 2007]. Crosses of Chy mice with Vegfr3+/- mice resulted in no liveborn offspring carrying both mutations, as those embryos were growth retarded at E10.5 and died around the same time as the Vegfr3-/- mice [Karkkainen et al., 2001]. These results further support the idea that there is no signalling via the mutant p.lle1053Phe-Vegfr3 receptor.

Interestingly, we have recently identified a MD patient (Ped 30, Table 1) with the same p.lle1053Phe mutation as the Chy mouse. This female patient presented with congenital lymphoedema of both feet. She does not have a history of chylous ascites or other systemic lymphatic impairment. Her son was noted to have oedema of both feet on pre-natal ultrasound imaging, but had no signs of hydrops fetalis. He was later born with lymphoedema confined to both feet. Like the Chy mice, MD patients with heterozygous VEGFR3 mutations also present with swelling of the limbs. Chy mice show other similarities with the human MD phenotype. For example, lymphoscintigraphy in MD patients shows no transport of dyes injected subcutaneously at the site of oedema, indicating lack of functional 
peripheral lymphatics [Brice et al., 2005]. Similarly, fluid transport is compromised in the Chy mice [Karkkainen et al., 2001]. However unlike Chy mice the presence of initial dermal lymphatics can be demonstrated in humans but they are non-functional [Mellor et al., 2010]. Furthermore, as mentioned earlier, Chy mice were also found to present with chylous ascites which then resorbed postnatally. This has been reported in MD patients [Ghalamkarpour et al., 2009a] although it is very uncommon. Furthermore, it has been demonstrated that overexpression of VEGFR3 ligands could induce lymphatic vessel growth in Chy mice [Karkkainen et al., 2001], and recent experiments in large animal models combining lymph node transfer and VEGFC therapy have shown promising results in restoring the lymphatic network [Lähteenvuo et al., 2011]. Therefore, the finding of the Chy mouse mutation, p.lle1053Phe in a human lymphoedema patient confirms the validity of this mouse model in studies of lymphoedema.

Transgenic mouse lines with features similar to human lymphoedema have been developed, and overexpression studies show that growth of lymphatic vessels can be inhibited. It was concluded that continuous VEGFR3 signalling is required during development and maintenance of the lymphatic system [Makinen et al., 2001]. This study also demonstrated that neonatal mice lacking lymphatic vessels in several internal organs will regrow these postnatally, indicating that lymphatic regeneration can occur. This postnatal lymphatic maturation mechanism in the visceral organs, but not in the skin, has also been described by Karpanen et al. [2006] and it confirms the necessity for VEGFC/VEGFR3 signalling during the first few weeks after birth. Karkkainen et al. [2001] found that in mice, NRP2 interacts with VEGFC to develop lymphatic vessels in visceral organs but not in skin, suggesting that cutaneous lymphatic vessels are regulated differently from other organs. 
The majority of MD patients described in the literature have heterozygous missense mutations in VEGFR3. Expression studies have shown that mutations in VEGFR3 observed in MD patients lead to proteins with inactive tyrosine kinase domains, which means the receptor fails to transduce signal from its ligands in the LECs and this prevents downstream gene activation [Karkkainen et al., 2000; Irrthum et al., 2000]. Although mutations in VEGFR3 block tyrosine kinase function, Karkkainen et al. [2000] showed that WT receptors can transphophorylate the mutant receptor to some extent. VEGFR3 mutation positive patients therefore retain some receptor activity, and it is suggested that mutant VEGFR3 acts in a dominant-negative manner in the heterodimerized receptors. A further observation was that mutant receptors do not get internalized as rapidly as the WT receptors, and it was speculated that this could contribute to the lymphoedema phenotype.

Tadpoles and zebrafish have also proved useful animal models for studies of lymphatic development. Evidence has been provided from both that lymph vessels express VEGFR3 and that LECs derive from primitive veins [Ny et al., 2005; Yaniv et al., 2006]. As with the mouse model, knockdown of VEGFR3 in tadpoles impairs lymph vessel formation and function, and the frog embryos develop oedema [Ny et al., 2008]. Zebrafish can also develop severe oedema when the VEGFC/VEGFR3 signalling is disturbed, indicating that this system is controlling lymphangiogenesis in the zebrafish [Kuchler et al., 2006].

A lot of work has been conducted to try and understand the role of VEGFR3 in lymphatic development, but fewer studies have focused on what happens in the adult lymphatics. One such approach looked at skin biopsies from VEGFR3 mutation positive MD patients and 
found that lymphangiogenesis must have taken place, as lymphatics were present in the skin although at a reduced density [Mellor et al., 2010]. However, absorption and transport of injected dye by the initial lymphatics in the lower feet is completely absent, indicating that VEGFR3 also has a functional role. How VEGFR3 alters the functioning of the adult lymphatics is not clear, nor why lymphatic function is only altered in the lower limbs and feet, and not the whole body. More studies need to be undertaken to elucidate this.

It is interesting to note from the work of Mellor et al. [2010] that those VEGFR3 mutation positive individuals with a family history of MD but no clinically detectable lymphoedema themselves, showed a similar pattern of normal absorption and transportation of the injected dye to the controls. However, these mutation carriers did have saphenous vein reflux. This pattern of venous incompetence is not uncommon in the MD patients we have examined [see Table 2 and Brice et al., 2005], and recent gene expression studies [Bazigou et al., 2011] have revealed that Vegfr3 is present in developing mouse venous valves. It is therefore possible that VEGFR3 has a role in venous development as well as lymphatic development [Covassin et al., 2006 and Hogan et al., 2009].

VEGFR3 not only plays a role during embryonic development, it also has a postnatal function. Typically at sites of tissue inflammation (e.g. during wound healing) and in cancer, VEGFR3 is upregulated via mediation by PROX1 and NF-KB, making the tyrosine receptor more sensitive to VEGFC and VEGFD. This induces lymphangiogenesis at the site of inflammation [Flister et al., 2010]. This expansion of the lymphatic network during inflammation provides new routes to facilitate the immune response [Baluk et al., 2005]. 
When expressed in non-endothelial cells, VEGFR3 has been shown to have anti-angiogenic properties in inflammatory corneal angiogenesis [Cursiefen et al., 2006] and apparently VEGFR3/VEGFC signalling also acts on neural stem cells and regulates adult neurogenesis [Calvo et al., 2011]. Without doubt much more is to be learnt about the role of VEGFR3.

\section{Clinical and Diagnostic Relevance}

Historically, all congenital primary lymphoedema was classified as Milroy Disease (MD). Recent intensive clinical research has shown that the classification of patients with lymphoedema should be much more rigorous [Connell et al., 2010]. Identification of mutations in VEGFR3 gives a definite diagnosis in patients with $M D$, but the absence of a mutation does not exclude the diagnosis.

A molecular diagnosis allows for reliable genetic counselling and the SW Thames Molecular Genetics Diagnostic Laboratory has been offering molecular genetic testing for VEGFR3 mutations since 2006. Testing is performed on exons 17 to 26 of the VEGFR3 gene as these encode the two functional TK domains of the protein. Initially this was performed using the combined approach of pre-screening using dHPLC on transgenomic WAVE and subsequent sequence analysis of variants. Since 2008 testing has been by sequence analysis of all 10 exons and exon-intron boundaries, set up using the Biomek NX robots and analysed on the $A B I 3130$. If a variant is identified in a patient, several types of analyses are performed to determine its pathogenicity. The variant is checked against an in house patient mutation list and published data to ascertain if it has been reported in MD families previously. Any novel changes are checked in approximately 200 control samples. The variant is also entered on to the Alamut software database (www.interactive-biosoftware.com), which runs several 
prediction programs (such as PolyPhen-2, SIFT and AlignGVGD) that predict the likely effect of the missense mutation on the VEGFR3 protein. Variants predicted to affect splicing can also be checked using this software which automatically feeds information into a range of integrated splice prediction programs. Taking all these lines of evidence, a diagnosis of MD is either confirmed, or other family members are requested in order to help determine the pathogenicity of the variant.

Analysis of VEGFR3 in MD patients has revealed molecular heterogeneity, with 58 different mutations distributed along the TK domains of the gene. The SGH lab has analysed 192 index patients and found mutations in 66 patients (34\%). Lack of mutations in patients referred for MD diagnostic testing are explicable by several reasons; firstly some samples were submitted to exclude MD, secondly due to the fact that referrals are received from a wide range of clinicians, not all of whom are experienced in diagnosing patients with MD, and finally MD is extremely variable so the diagnostic criteria for testing has in the past been unclear. In patients evaluated by our clinical team and fulfilling classical Milroy diagnostic criteria, mutations have been found in $70 \%$ of cases [Connell et al., 2009] suggesting that mutations in VEGFR3 are the major cause of MD. A diagnostic problem arises if no mutations are found in VEGFR3 as no other gene for MD has been identified so far. 


\section{Genotype/phenotype correlation}

MD patients show extreme variability of the clinical presentation and no genotypephenotype correlations have been defined. This variability has been observed within families carrying the same mutation, as well as between families, suggesting that environmental factors and/or genetic modifiers contribute to the phenotype.

\section{Future Prospects}

We believe that it is necessary to promote both a better knowledge of this disease and a reappraisal of clinical criteria to undertake molecular analysis. A more extensive description of the clinical phenotype of MD patients, together with their mutational genotype, might provide insight into genotype-phenotype correlations and the existence of possible modifier genes. We believe that the availability of the extended clinical findings in VEGFR3 mutation carriers as in the FLT4-LOVD database, allows for better understanding of the disease. At the biochemical level further elucidation of the function of VEGFR3 will be necessary to understand the disease mechanism. Reliable exclusion of VEGFR3 as the cause of congenital swelling in some patients may lead to the identification of further genes presenting in this way. Finally, a better understanding of the function of VEGFR3 will allow the development of therapies that will be more specific and effective than current treatments. 


\section{Acknowledgements}

All authors declare there is no conflict of interest. KG is supported by British Heart Foundation Clinical Research Training Fellowship (FS/11/40/28739) and PO is supported by British Heart Foundation Project Grant (PG/10/58/28477).

\section{References}

Baldwin ME, Halford MM, Roufail S, Williams RA, Hibbs ML, Grail D, Kubo H, Stacker SA, Achen MG. 2005. Vascular endothelial growth factor D is dispensable for development of the lymphatic system. Mol Cell Biol 25:2441-2449.

Baluk P, Tammela T, Ator E, Lyubynska N, Achen MG, Hikclin DJ, Jeltsch M, Petrova TV, Pytowski B, Stacker SA, Ylä-Herttuala, Jackson DG, AlitaloK, McDonald DAet al. 2005. Pathogenesis of persistent lymphatic vessel hyperplasia in chronic airway inflammation. J Clin Invest 115:247-257.

Bazigou E, Lyons OTA, Smith A, Venn GE, Cope C, Brown NA, Makinen T. 2011. Genes regulating lymphangiogenesis control venous valve formation and maintenance in mice. J Clin Invest 121:2984-2992.

Brice G, Child AH, Evans A, Bell R, Mansour S, Burnand K, Sarfarazi M, Jeffery S, Mortimer P. 2005. Milroy disease and the VEGFR-3 mutation phenotype. J Med Genet 42:98-102.

Brice G, Mansour S, Bell R, Collin JRO, Child AH, Brady AF, Sarfarazi M, Burnand KG, Jeffery S, Mortimer P, Murday VA. 2002. Analysis of the phenotypic abnormalities in lymphoedemadistichiasis syndrome in 74 patients with FOXC2 mutations or linkage to 16q24. J Med Genet 39:478-483. 
Butler MG, Dagenais SL, Rockson SG, Glover TW. 2007. A novel VEGFR3 mutation causes Milroy Disease. Am J Med Genet A 143A:1212-1217.

Calvo CF, Fontaine RH,_Soueid J, Tammela T, Makinen T, Alfaro-Cervello C, Bonnaud F, Miguez A, Benhaim L, Xu Y, Barallobre MJ, Moutkine I, Lytikkä J, Tatlisumak T, PytowskiB, Zale B, Richardson W, Kessaris N, Garcia-Verdugo JA, Alitalo K, Eichmann A, Thomas JL.Et al. 2011. Vascular endothelial growth factor receptor 3 directly regulates murine neurogenesis. Genes Dev 25:831-844.

Carver C, Brice G, Mansour S, Ostergaard P, Mortimer P, Jeffery S. 2007. Three children with Milroy disease and de novo mutations in VEGFR3. Clin Genet 71:187-189.

Connell F, Brice G, Jeffery S, Keeley V, Mortimer P, Mansour S. A new classification system for primary lymphatic dysplasias based on phenotype. 2010. Clin Genet 77:438-452.

Connell F, Ostergaard P, Carver C, Brice G, Williams N, Mansour S, Mortimer PS, Jeffery S, lymphoedema consortium. 2009. Analysis of the coding regions of VEGFR3 and VEGFC in Milroy disease and other primary lymphoedemas. Hum Genet 124:625-631

Cursiefen C, Chen L, Saint-Geniez M, Hamrah P, Jin Y, Rashid S, Pytowski B, Persaud K, Wu Y, Streilein W, Dana R. 2006. Nonvascular VEGF receptor 3 expression by corneal epithelium maintains avascularity and vision. PNAS 103:11405-11410.

Daniel-Spiegel E, Ghalamkarpour A, Spiegel R, Weiner E, Vikkula M, Shalev E, Shalev SA. 2005. Hydropsfetalis: an unusual presentation of hereditary congenital lymphedema. PrenatDiagn 25:1015-1018. 
Dellinger MT, Hunter RJ, Bernas MJ, Witte MH, Erickson RP. 2007. Chy-3 mice are Vegfchaploinsufficient and exhibit defective dermal superficial to deep lymphatic transition and dermal lymphatic hypoplasia. DevDyn 236:2346-2355.

Dumont DJ, Jussila L, Taipale J, Lymboussaki A, Mustonen T, Pajusola K, Breitman M, Alitalo K. 1998. Cardiovascular failure in mouse embryos deficient in VEGF receptor-3. Science 282:946-949.

Evans AL, Bell R, Brice G, Comeglio P, Lipede C, Jeffery S, Mortimer P, Sarfarazi M, Child AH. 2003. Identification of eight novel VEGFR-3 mutations in families with primary congenital lymphoedema. J Med Genet 40:697-703.

Evans AL, Brice G, Sotirova V, Mortimer P, Beninson J, Burnand K, Rosbotham J, Child A, Sarfarazi M. 1999. Mapping of primary congenital lymphedema to the $5 q 35.3$ region. Am J Hum Genet 64:547-555.

Ferrell RE, Levinson KL, Esman JH, Kimak MA, Lawrence EC, Barmada MM, Finegold DN. 1998. Hereditary lymphedema: evidence for linkage and genetic heterogeneity. Human Molecular Genetics 13:2073-2078.

Flister MJ, Wilber A, Hall KL, Iwata C, Miyazono K, Nisato RE, Pepper MS, Zawieja DC, Ran S. 2010. Inflammation induces lymphangiogenesis through up-regulation of VEGFR-3 mediated by NF-KB and Prox1. Blood 115:418-429.

Fokkema IF, den Dunnen JT, Taschner PE. 2005. LOVD: easy creation of a locus-specific sequence variation database using an "LSDB-in-a-box" approach. Hum Mutat 26:63-68. Francois M, Caprini A, Hosking B, Orsenigo F, Wilhelm D, Browne C, Paavonen K, Karnezis T, Shayan R, Downes M, Davidson T, Tutt D, Cheah K, Stacker SA, Muscat GEO, Achen MG, 
Dejana E, Koopman Pet al. 2008. Sox18 induces development of the lymphatic vasculature in mice. Nature 456: 643-648.

Futatani T, Nii E, Obata M, Ichida F, Okabe Y, Kanegane H, Miaywaki T. 2008. Molecular characterization of two novel VEGFR3 mutations in Japanese families with Milroy's disease. PediatrInt 50:116-118.

Ghalamkarpour A, Debauche C, Haan E, Van Regemorter N, Sznajer Y, Thomas D, Revencu N, Gillerot Y, Boon LM, Vikkula M. 2009a. Sporadic in utero generalized edema caused by mutations in the lymphangiogenic genes VEGFR3 and FOXC2. J Pediatr 155:90-93.

Ghalamkarpour A, Holnthoner W, Saharinen P, Boon LN, Mulliken JB, Alitalo K, Vikkula M. 2009b. Recessive primary congenital lymphoedema caused by a VEGFR3 mutation. J Med Genet 46:399-404.

Ghalamkarpour A, Morlot S, Raas-Rothschild A, Utkus A, Mulliken JB, Boon LM, Vikkula M. 2006. Hereditary lymphedema type 1 associated with VEGFR3 mutation: the first de novo case and atypical presentations. Clin Genet 70:330-335.

HaikoP, Maiken T, Keskitalo S, Taipale J, Karkkainen M, Baldwin ME, Stacker SA, Achen MG, Alitalo K. 2008. Deletion of vascular endothelial growth factor C (VEGF-C) and VEGF-D is not equivalent to VEGF Receptor 3 deletion in mouse embryos. 2008. Mol Cell Biol 28:48434850.

Hogan BM, Herper R, Witte M, Heloterä H, Alitalo K, Duckers HJ, Schulte-Merker S. 2009. Vegfc/Flt4 signalling is suppressed by DII4 in developing zebrafishintersegmental arteries. Development 136:4001-4009. 
HolbergCJ, Erickson RP, Bernas MJ, Witte MH, Fultz KE, Andrade M, Witte CL. 2001.

Segregation analyses and a genome-wide linkage search confirm genetic heterogeneity and suggest oligogenic inheritance in some Milroy congenital primary lymphedema families. Am J Med Genet 98:303-312

Iljin K, Karkkainen MJ, Lawrence EC, Kimak MA, Uutela M, Taipale J, Pajusola K, Alhonen L, Halmekytö M, Finegold DN, Ferrell RE, Alitalo K. 2001. VEGFR3 gene structure, regulatory region and sequence polymorphisms. FASEB J 15:1028-1036.

Irrthum A, Karkkainen MJ, Devriendt K, Alitalo K, Vikkula M. 2000. Congenital hereditary lymphedema caused by a mutation that inactivates VEGFR3 tyrosine kinase. Am J Hum Genet 67:295-301.

Joukov V, Pajusola K, Kaipainen A, Chilow D, Lahtinen I, Kukk E, Saksela O, Kalkkinen N, Alitalo K. 1996. A novel vascular endothelial growth factor, VEGF-C, is a ligand for the Flt4 (VEGFR-3) and KDR (VEGFR-2) receptor tyrosine kinases. EMBO J 15:290-298.

Kaipanen A, Korhonen J, Mustonen T, van Hinsbergh VWM, Fang G-H, Dumont D, Breitman M, Alitalo K. 1995. Expression of the fms-like tyrosine kinase 4 gene becomes restricted to lymphatic endothelium during development. ProcNatIAcadSci USA 92:3566-3570.

Karkkainen MJ, Haiko P, Sainio K, Partanen J, Taipale J, Petrova TV, Jeltsch M, Jackson DG, Talikka M, Rauvala H, Betsholtz C, Alitalo K. 2004. Vascular endothelial growth factor C is required for sprouting of the first lymphatic vessels from embryonic veins. Nat Immunol 5:74-80.

Karkkainen M, Saaristo A, Jussila L, Karila KA, Lawrence EC, Pajusola K, Bueler H, Eichmann A, Kauppinen R, Kettunen M, Ylä-Herttuala S, Finegold DN, Ferrell RE, Alitalo Ket al. 2001. A model for gene therapy of human hereditary lymphedema. PNAS 98:12677-12682. 
Karkkainen MJ, Ferrell RE, Lawrence EC, Kimak MA, Levinson KL, McTigue MA, Alitalo K, Finegold DN. 2000. Missense mutations interfere with VEGFR-3 signalling in primary lymphoedema. Nat Genet 25:153-159.

Karpanen T, Wirzenius M, Mäkinen T, Veikkola T, Haisma HJ, Achen MG, Stacker SA, Pytowski B, Ylä-Herttuala S, Alitalo K. 2006. Lymphangiogenic growth factor responsiveness is modulated by postnatal lymphatic vessel maturation. Am J Pathol 169:708-718.

Kitsiou-Tzeli S, Vrettou C, Leze E, Makrythanasis P, Kanavakis E, Willem P. 2010. Milroy's primary congenital lymphedema in a male infant and review of the literature. 2010. In vivo 24:309-314.

Kuchler AM, Gjini E, Peterson-Maduro J, Cancilla B, Wolburg H, Schulte-Merker S. 2006. Development of the zebrafish lymphatic system requires Vegfc signalling. CurrBiol 16:12441248.

Lähteenvuo M, Honkonen K, Tervala T, Tammela T, Suominen E, Lähteenvuo J, Kholová I, Alitalo K, Ylä-Herttuala S, Saaristo A. 2011. Growth factor therapy and autologous lymph node transfer in lymphedema. Circulation 123:613-620.

Mäkinen T, Jussila L, Veikkola T, Karpanen T, Kettunen MI, Pulkanen KJ, Kauppinen R, Jackson DG, Kubo H, Nishikawa S-I, Ylä-Herttula S, Alitalo K. 2001. Inhibition of lymphangiogenesis with resulting lymphedema in transgenic mice expressing soluble VEGF receptor-3. Nat Med 7:199-205.

Mellor RH, Hubert CE, Stanton AWB, Tate N, Akhras V, Smith A, Burnand K, Jeffery S, Makinen T, Levick JR, Mortimer PS. 2010. Lymphatic dysfunction, not aplasia, underlies Milroy disease. Microcirculation 17:281-296. 
Milroy WF. 1892. An undescribed variety of hereditary oedema. N Y Med J 56:505-508.

Mizuno S, Yamada Y, Yamada K, Nomura N, Wakamatsu N. 2005. Clinical variability in a Japanese hereditary lymphedema type I family with an FLT4 mutation. CongenitAnom (Kyoto) 45:59-61.

Norrmen C, Tammela T, Petrova TV, Alitalo K. 2011. Biological basis of therapeutic lymphangiogenesis. Circulation 123:1335-1351.

Ny A, Kock M, Schneider M, Neven E, Tong RT, Maity S, Fischer C, Plaisance S, Lambrechts D, Héligon C, Terclaver S, Ciesiolka M, Kälin R, Man WY, Senn 1, Wyns S, Lupu F, Brändli A, Vleminckx K, Collen D, Dewerchin M, Conway EM, Moons L, Jain RK, Carmeliet Pet al. 2005. A genetic Xenopuslaevis tadpole model to study lymphangiogenesis. Nat Med 11:998-1004. Ny A, Kock M, Vandevelde W, Schneider M, Fischer C, Diez-Juan A, Neven E, Geudens I, Maity S, Moons L, Plaisance S, Lambrechts D, Carmeliet P, Dewerchin Met al. Role of VEGF-D and VEGFR-3 in developmental lymphangiogenesis, a chemicogenetic study in Xenopus tadpoles. Blood 112:1740-1749.

Pajusola K, Aprelikova O, Korhonen J, Kaipainen A, Pertovaara L, Alitalo R, Alitalo K. 1992. FLT4 receptor tyrosine kinase contains seven immunoglobulin-like loops and is expressed in multiple human tissues and cell lines. Cancer Res 52:5738-5743.

Schulte-Merker S, Sabine A, Petrova TV. 2011. Lymphatic vascular morphogenesis in development, physiology, and disease. J Cell Biol 193:607-618.

Schwarz JM, Rödelsperger C, Schuelke M, Seelow D. 2010. MutationTaster evaluates disease-causing potential of sequence alterations. Nat Methods 7:575-576. 
Spiegel R, Ghalamkarpour A, Daniel-Spiegel E, Vikkula M, Shalev SA. 2006. Wide clinical spectrum in a family with hereditary lymphedema type I due to a novel missense mutation in VEGFR3. J Hum Genet 51:846-850.

Tammela T, Zarkada G, Wallgard E, Murtomäki A, Suchting S, Wirzenius M, Waltari M, Hellström M, Schomber T, Peltonen R, Freitas C, Duarte A, Isoniemi H, Laakkonen P, Christofori G, Ylä-HerttualaS, Shibuya M, Pytowski B, Eichmann A, Betsholtz C, AlitaloK. et al. 2008. Blocking VEGFR-3 suppress angiogenic sprouting and vascular network formation. Nature 454:656-660.

Tammela T, Alitalo K. 2010. Lymphangiogenesis: Molecular mechanisms and future promise. Cell 140:460-476.

Verstraeten VLRM, Holnthoner W, van Steensel MAM, Veraart JCJM, Bladergroen RS, Heckman CA, Keskitalo S, Frank J, Alitalo K, van Geel M, Steijlen PM. 2009. Functional analysis of FLT4 mutations associated with Nonne-Milroy lymphedema. J Invest Dermatol 129:509-512.

Walter JW, North PE, Waner M, Mizeracki A, Blei F, Walker JWT, Reinisch JF, Marchuk DA. 2002. Somatic mutation of vascular endothelial growth factor receptors in juvenile hemangioma. 2002. Genes Chromosomes Cancer 33:295-303.

Wigle JT, Harvey N, Detmar M, Lagutina I, Grosveld G, Gunn MD, Jackson DG, Oliver G. 2002. An essential role for Prox1 in the induction of the lymphatic endothelial cell phenotype. EMBO J 21:1505-1513.

Wildeman M, van Ophuizen E, den Dunnen JT, Taschner PE. Improving sequence variant descriptions in mutation databases and literature using the MUTALYZER sequence variation nomenclature checker. Hum Mutat 29:6-13. 
Witte MH, Erickson R, Bernas M, Andrade M, Reiser F, Conlon W, Hoyme HE, Witte CL. 1998. Phenotypic and genotypic heterogeneity in familial Milroy lymphedema. Lymphology 31:145-155.

Yamada Y, Nezu J, Shimane M, Hirata Y. 1997. Molecular cloning of a novel vascular endothelial growth factor, VEGF-D. Genomics 42:483-488.

Yaniv K, Isogai S, Castranova D, Dye L, Hitomi J, Weinstein BM. 2006. Live imaging of lymphatic development in the zebrafish. Nat Med 12:711-716.

Yu Z, Wang J, Peng S, Dong B, Li Y. 2007. Identification of a novel VEGFR-3 missense mutation in a Chinese family with hereditary lymphedema type I. J Genet Genomics 34:861867 
Fig. 1. Schematic presentation of the VEGFR3 gene and positions of mutations causing Milroy Disease. Only the tyrosine kinase domains of the protein have been reported to harbour mutations, which are encoded for by exons 17 to 26 (dark grey/blue boxes, not to scale). * indicates the novel mutations reported in this paper. Recurrent mutations and how often they have been reported is indicated by numbers in brackets. ${ }^{\S}$ These two variants are from same patient and therefore not sure if both are causative. ${ }^{\ddagger}$ This variant is possibly only causing an effect in the homozygous state. 
Figure 1:

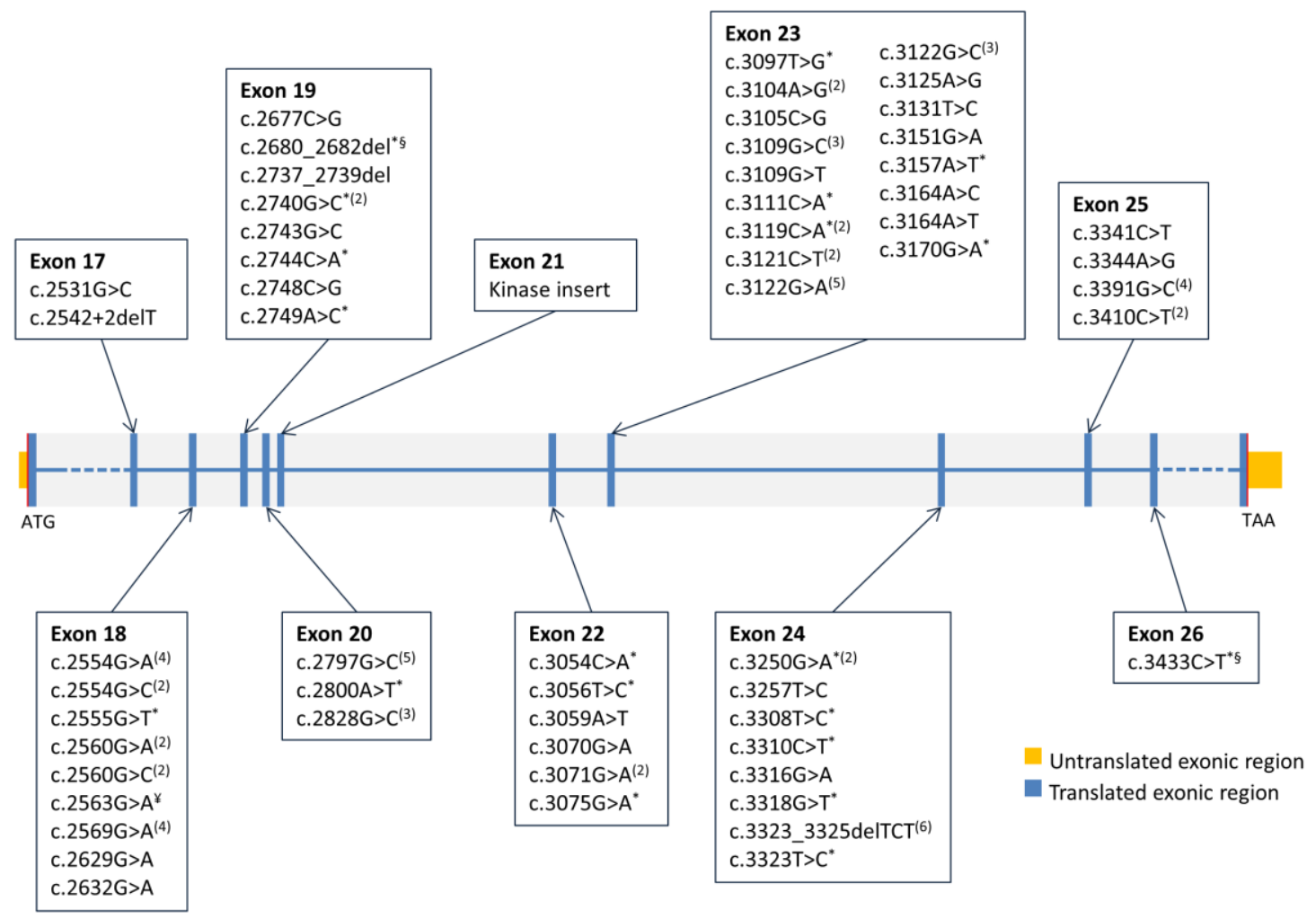


Table 1. Genetic and clinical summary of 43 previously unreported VEGFR3-mutation-positive patients including 19 with new, unreported variants (indicated with *). $\S$ = Patient not seen at St George's Hospital (i.e. DNA sent for screening in SGH's diagnostic service). A hyphen (-) indicates unknown as not examined by the authors or information not provided by referring clinician; $C=$ onset at age $<1$ year; $Y=$ yes; $N=$ no; $B=$ bilateral lower limbs, $U R=$ unilateral right leg, $\mathrm{UL}=$ unilateral left leg, $\mathrm{F}=$ foot, $\mathrm{FA}=$ foot and ankle, $\mathrm{FAC}=$ foot, ankle and calf, $\mathrm{BH}=$ bilateral hydrocoele, $\mathrm{R}=$ right, $\mathrm{T}=$ typical of Milroy, $A=$ atypical. Numbers in brackets indicate number of additional affected family members. Notice pedigree 8 carries two unreported variants, and pedigree 30 has the same mutation as the Chy mouse.

\begin{tabular}{|c|c|c|c|c|c|c|c|c|c|c|c|c|c|c|}
\hline Ped & Exon & Nucleotide change & Protein change & Gender & Onset & $\mathrm{FHx}$ & $\begin{array}{c}\text { Site } \\
\text { Affected }\end{array}$ & $\begin{array}{l}\text { Extent of } \\
\text { swelling }\end{array}$ & $\begin{array}{l}\text { Hydro- } \\
\text { coele }\end{array}$ & $\begin{array}{l}\text { Lymph } \\
\text { scan } \\
\text { findings }\end{array}$ & $\begin{array}{c}\text { Radiological } \\
\text { evidence of } \\
\text { varicose } \\
\text { veins }\end{array}$ & $\begin{array}{c}\text { Clinical } \\
\text { evidence } \\
\text { of } \\
\text { prominent } \\
\text { veins } \\
\end{array}$ & $\begin{array}{l}\text { Upslan- } \\
\text { ting } \\
\text { toenails }\end{array}$ & Additional comments \\
\hline 1 & 18 & c. $2554 \mathrm{G}>\mathrm{A}$ & p.(Gly852Ser) & Female & c & $\mathrm{Y}(3)$ & B & $\mathrm{F}$ & & - & - & $\mathrm{N}$ & - & Distant cousin of Ped 2. \\
\hline 2 & 18 & c. $2554 \mathrm{G}>\mathrm{A}$ & p.(Gly852Ser) & Male & c & $\mathrm{Y}(1)$ & UR & $\mathrm{F}$ & $\mathrm{N}$ & - & - & - & - & Distant cousin of Ped1. \\
\hline 3 & 18 & c. $2554 \mathrm{G}>\mathrm{A}$ & p.(Gly852Ser) & Male & c & $\mathrm{Y}$ & B & $\mathrm{F}$ & - & - & - & - & - & Father is an asymptomatic carrier. \\
\hline 4 & 18 & c. $2554 \mathrm{G}>\mathrm{C}$ & p.(Gly852Arg) & Male & $\mathrm{c}$ & $\mathrm{Y}(6)$ & $B$ & $\mathrm{~F}$ & $\mathrm{~N}(2)$ & $T$ & - & $\mathrm{Y}$ & $\mathrm{Y}$ & \\
\hline $5^{5}$ & $18^{*}$ & $c .2555 \mathrm{G}>\mathrm{T}$ & p.(Gly852Val) & Female & - & - & - & - & & - & - & - & - & \\
\hline $6^{5}$ & 18 & c. $2560 \mathrm{G}>\mathrm{C}$ & p.(Gly854Arg) & Female & - & $\mathrm{Y}$ & B & $\mathrm{F}$ & & - & - & - & - & \\
\hline $7^{5}$ & 18 & $c .2569 \mathrm{G}>\mathrm{A}$ & p.(Gly857Arg) & Female & - & $\mathrm{Y}(2)$ & - & - & & - & - & - & - & $\begin{array}{l}\text { Fetus died with hydrops fetalis. } \\
\text { Third pregnancy with pleural effusions which resolved. }\end{array}$ \\
\hline 8 & $19 * / 26^{*}$ & $\begin{array}{c}\text { c. } 2680 \_2682 \mathrm{del} / \\
\text { c.3433C>T }\end{array}$ & $\begin{array}{l}\text { p.(Met894del)/ } \\
\text { p.(Arg1145Cys) }\end{array}$ & Female & c & $\mathrm{Y}(1)$ & B & FAC & (1) & - & - & $\mathrm{Y}$ & Y & \\
\hline 9 & $19^{*}$ & c. $2740 \mathrm{G}>\mathrm{C}$ & p.(Gly914Arg) & Male & c & $\mathrm{N}$ & B & $\mathrm{F}$ & $\mathrm{N}$ & - & - & $\mathrm{Y}$ & - & \\
\hline 10 & $19^{*}$ & c. $2740 \mathrm{G}>\mathrm{C}$ & p.(Gly914Arg) & Male & c & $\mathrm{N}$ & B & $\mathrm{F}$ & $\mathrm{BH}$ & - & - & $\mathrm{Y}$ & $\mathrm{Y}$ & \\
\hline 11 & $19^{*}$ & c. $2744 C>A$ & p.(Ala915Glu) & Male & c & $\mathrm{Y}(2)$ & B & $\mathrm{F}$ & $\mathrm{R}$ & - & - & $\mathrm{N}$ & $\mathrm{Y}$ & \\
\hline $12^{5}$ & $19^{*}$ & c. $2749 A>C$ & p.(Thr917Pro) & Female & - & $Y$ & - & - & & - & - & - & - & \\
\hline 13 & 20 & c. $2797 \mathrm{G}>\mathrm{C}$ & p.(Gly933Arg) & Female & $\mathrm{C}$ & $\mathrm{Y}(2)$ & B & FA & & - & - & Y & - & $\begin{array}{l}\text { Epicanthic folds. } \\
\text { Mother is an asymptomatic carrier. }\end{array}$ \\
\hline $14^{5}$ & $20^{*}$ & c. $2800 A>T$ & p.(Asn934Tyr) & - & - & - & - & - & - & - & - & - & - & \\
\hline 15 & 20 & $c .2828 \mathrm{G}>\mathrm{C}$ & p.(Arg943Pro) & Male & c & $\mathrm{Y}(4)$ & UR & $\mathrm{F}$ & $\mathrm{N}$ & - & - & $\mathrm{N}$ & - & Mother and uncle are asymptomatic carriers. \\
\hline 16 & 20 & c. $2828 \mathrm{G}>\mathrm{C}$ & p.(Arg943Pro) & Female & C & $Y(3)$ & B & FA & & - & - & $\mathrm{Y}$ & Y & $\begin{array}{l}\text { Epicanthic folds. } \\
\text { Distant cousin published in Connell et al. (2009). }\end{array}$ \\
\hline $17^{5}$ & $22^{*}$ & c. $3054 C>A$ & p.(Ser1018Arg) & - & - & $\mathrm{Y}$ & - & - & - & - & - & - & - & \\
\hline $18^{5}$ & $22^{*}$ & c. $3056 \mathrm{~T}>\mathrm{C}$ & p.(Phe1019Ser) & Male & - & $Y$ & - & - & - & - & - & - & - & \\
\hline $19^{5}$ & $22^{*}$ & c. $3075 \mathrm{G}>\mathrm{A}$ & p.(Met1025lle) & Male & - & $\mathrm{Y}$ & - & - & - & - & - & - & - & \\
\hline 20 & $23^{*}$ & c.3097T>G & p.(Cys1033Gly) & Female & C & $Y(4)$ & $\mathrm{B}$ & FAC & (1) & $T$ & $Y$ & $Y$ & $\mathrm{Y}$ & \\
\hline $21^{5}$ & 23 & c. $3104 \mathrm{~A}>\mathrm{G}$ & p.(His1035Arg) & Female & - & - & - & - & & - & - & - & - & \\
\hline $22^{5}$ & 23 & c. $3109 \mathrm{G}>\mathrm{C}$ & p.(Asp1037His) & Male & c & - & - & - & - & - & - & - & - & \\
\hline 23 & $23^{*}$ & c. $3111 \mathrm{C}>\mathrm{A}$ & p.(Asp1037Glu) & Female & c & $\mathrm{Y}(1)$ & B & FA & & - & - & $\mathrm{Y}$ & $\mathrm{Y}$ & \\
\hline
\end{tabular}




\begin{tabular}{|c|c|c|c|c|c|c|c|c|c|c|c|c|c|c|}
\hline Ped & Exon & Nucleotide change & Protein change & Gender & Onset & $\mathrm{FHx}$ & $\begin{array}{c}\text { Site } \\
\text { Affected }\end{array}$ & $\begin{array}{l}\text { Extent of } \\
\text { swelling }\end{array}$ & $\begin{array}{l}\text { Hydro- } \\
\text { coele }\end{array}$ & $\begin{array}{l}\text { Lymph } \\
\text { scan } \\
\text { findings }\end{array}$ & $\begin{array}{c}\text { Radiological } \\
\text { evidence of } \\
\text { varicose } \\
\text { veins }\end{array}$ & $\begin{array}{c}\text { Clinical } \\
\text { evidence } \\
\text { of } \\
\text { prominent } \\
\text { veins } \\
\end{array}$ & $\begin{array}{l}\text { Upslan- } \\
\text { ting } \\
\text { toenails }\end{array}$ & Additional comments \\
\hline $24^{\S}$ & $23^{*}$ & c. $3119 \mathrm{C}>\mathrm{A}$ & p.(Ala1040Asp) & Male & - & $\mathrm{Y}(2)$ & - & - & - & - & & - & & $\begin{array}{l}\text { Learning difficulties and behavioural problems. } \\
\text { Father is an asymptomatic carrier. }\end{array}$ \\
\hline $25^{5}$ & $23^{*}$ & c. $3119 C>A$ & p.(Ala1040Asp) & Male & - & $\mathrm{Y}$ & - & - & - & - & - & - & - & \\
\hline 26 & 23 & c. $3122 \mathrm{G}>\mathrm{A}$ & p.(Arg1041Gln) & Female & c & $Y(1)$ & B & $\mathrm{F}$ & & A & $\mathrm{Y}$ & $\mathrm{Y}$ & - & Two episodes of cellulitis. \\
\hline 27 & 23 & c. $3122 \mathrm{G}>\mathrm{A}$ & p.(Arg1041Gln) & Female & $\mathrm{C}$ & $\mathrm{Y}(3)$ & $B$ & $\mathrm{FA}$ & & - & - & $Y$ & - & \\
\hline 28 & 23 & c. $3122 \mathrm{G}>\mathrm{C}$ & p.(Arg1041Pro) & Female & c & $Y(4)$ & B & $\mathrm{F}$ & & A & $\mathrm{Y}$ & $\mathrm{Y}$ & $\mathrm{Y}$ & \\
\hline 29 & 23 & c. $3122 \mathrm{G}>\mathrm{C}$ & p.(Arg1041Pro) & Male & c & $\mathrm{Y}(4)$ & B & FAC & BH & $T$ & - & $\mathrm{Y}$ & - & Persistent plantar warts. \\
\hline 30 & $23^{*}$ & c.3157A>T & p.(lle1053Phe) & Female & c & $\mathrm{N}$ & B & FAC & & $\mathrm{T}$ & $\mathrm{Y}$ & $\mathrm{N}$ & - & Persistent plantar warts. \\
\hline 31 & $23^{*}$ & c. $3170 \mathrm{G}>\mathrm{A}$ & p.(Gly1057Asp) & Female & c & $Y(1)$ & B & $\mathrm{F}$ & & - & - & $\mathrm{N}$ & - & One episode of cellulitis. \\
\hline 32 & $24^{*}$ & $c .3250 \mathrm{G}>\mathrm{A}$ & p.(Glu1084Lys) & Female & c & $\mathrm{N}$ & UL & $\mathrm{F}$ & & $\mathrm{T}$ & - & $\mathrm{N}$ & - & Bilateral duplex kidneys. \\
\hline 33 & $24^{*}$ & c. $3250 \mathrm{G}>\mathrm{A}$ & p.(Glu1084Lys) & Female & c & $\mathrm{Y}(2)$ & B & $\mathrm{F}$ & (1) & - & - & $\mathrm{N}$ & $\mathrm{Y}$ & Two episodes of cellulitis. \\
\hline $34^{5}$ & $24^{*}$ & $\mathrm{c} .3308 \mathrm{~T}>\mathrm{C}$ & p.(Leu1103Pro) & Male & - & $Y(3)$ & - & - & - & - & - & - & - & \\
\hline 35 & $24^{*}$ & c. $3310 \mathrm{C}>\mathrm{T}$ & p.(Leu1104Phe) & Male & c & Y & B & FAC & $\mathrm{N}$ & - & - & $\mathrm{Y}$ & $\mathrm{Y}$ & \\
\hline $36^{5}$ & $24^{*}$ & $c .3318 \mathrm{G}>\mathrm{T}$ & p.(Glu1106Asp) & Female & $\mathrm{c}$ & $\mathrm{Y}$ & - & - & & - & - & - & - & \\
\hline 37 & 24 & c.3323_3325delTCT & p.(Phe1108del) & Male & c & $\mathrm{Y}(2)$ & B & $\mathrm{F}$ & $N(1)$ & - & - & $\mathrm{N}$ & - & $\begin{array}{l}\text { Born prematurely at } 32 \text { weeks gestation with } \\
\text { generalised swelling, which rapidly resolved at birth. }\end{array}$ \\
\hline 38 & 24 & c.3323_3325delTCT & p.(Phe1108del) & Male & $\mathrm{C}$ & $\mathrm{Y}(3)$ & $B$ & $\mathrm{~F}$ & $\mathrm{~N}$ & - & - & $Y$ & $Y$ & \\
\hline 39 & 24 & c.3323_3325delTCT & p.(Phe1108del) & Male & c & $Y(1)$ & B & $\mathrm{F}$ & $\mathrm{N}$ & T & $\mathrm{Y}$ & Y & $\mathrm{Y}$ & \\
\hline 40 & $24 *$ & c. $3323 \mathrm{~T}>\mathrm{C}$ & p.(Phe1108Ser) & Female & c & $\mathrm{N}$ & B & FA & & - & - & $\mathrm{Y}$ & $\mathrm{Y}$ & Epicanthic folds. \\
\hline 41 & 25 & c. $3391 \mathrm{G}>\mathrm{C}$ & p.(Gly1131Arg) & Female & c & $Y(1)$ & B & $\mathrm{F}$ & & - & - & $\mathrm{N}$ & Y & \\
\hline $42^{5}$ & 25 & c. $3391 \mathrm{G}>\mathrm{C}$ & p.(Gly1131Arg) & - & - & - & - & - & - & - & - & - & - & \\
\hline $43^{5}$ & 25 & c. $3391 \mathrm{G}>\mathrm{C}$ & p.(Gly1131Arg) & - & - & - & - & - & - & - & - & - & - & \\
\hline
\end{tabular}


Table 2. Summary of 38 known VEGFR3 mutations in 52 pedigrees taken from various reports: ${ }^{\mathrm{a}}$ Butler et al., 2007; ${ }^{\mathrm{b}} \mathrm{Carver}$ et al., 2007; ${ }^{\mathrm{C} C o n n e l l ~ e t ~ a l ., ~ 2009 ; ~}{ }^{\mathrm{d}}$ Evans et al., 2003; ${ }^{\mathrm{e}}$ Ghalamkarpour et al., 2006; 'Ghalamkarpour et al., 2009a; ${ }^{\mathrm{g}}$ Ghalamkarpour et al., 2009b; ${ }^{\mathrm{h}}$ Ferrell et al., 1998; ' ${ }^{\mathrm{F}}$ Futatani et al., 2008; 'Irrthum et al., 2000; 'Karkkainen et al., 2000; 'Kitsiou-Tzeli et al., 2010; ${ }^{\mathrm{m}}$ Mizuno et al., 2005; " Spiegel et al., 2006; ${ }^{\circ}$ Verstraeten et al., 2009; ${ }^{\mathrm{p}} \mathrm{Yu}$ et al., 2007. ${ }^{\mathrm{S}} \mathrm{This}$ missense mutation is possibly only causing an effect in the homozygous state.

\begin{tabular}{|c|c|c|c|}
\hline Exon & Nucleotide variant & Protein variant & Number of reports \\
\hline 17 & c. $2531 G>C$ & p.(Arg844Pro) & $1^{\mathrm{c}}$ \\
\hline $17 i$ & c.2542+2delT & & $1^{i}$ \\
\hline 18 & c. $2554 \mathrm{G}>\mathrm{A}$ & p.(Gly852Ser) & $1^{\mathrm{c}}$ \\
\hline 18 & c. $2554 \mathrm{G}>\mathrm{C}$ & p.(Gly852Arg) & $1^{\mathrm{c}}$ \\
\hline 18 & c. $2560 G>A$ & p.(Gly854Ser) & $2^{d}$ \\
\hline 18 & c. $2560 \mathrm{G}>\mathrm{C}$ & p.(Gly854Arg) & $1^{c}$ \\
\hline 18 & c. $2563 G>A$ & p.(Ala855Thr) & $1^{\mathrm{gS}}$ \\
\hline 18 & c. $2569 \mathrm{G}>\mathrm{A}$ & p.(Gly857Arg) & $3^{c, k, m}$ \\
\hline 18 & c. $2629 \mathrm{G}>\mathrm{A}$ & p.(Ala877Thr) & $1^{i}$ \\
\hline 18 & c. $2632 \mathrm{G}>\mathrm{A}$ & p.(Val878Met) & $1^{\mathrm{e}}$ \\
\hline 19 & c. $2677 C>G$ & p.(Leu893Val) & $1^{f}$ \\
\hline 19 & c.2737_2739del & p.(Leu913del) & $1^{b}$ \\
\hline 19 & c. $2743 G>C$ & p.(Ala915Pro) & $1^{d}$ \\
\hline 19 & c. $2748 \mathrm{C}>\mathrm{G}$ & p.(Cys916Trp) & $1^{d}$ \\
\hline 20 & c. $2797 \mathrm{G}>\mathrm{C}$ & p.(Gly933Arg) & $4^{c, d, o}$ \\
\hline 20 & c. $2828 \mathrm{G}>\mathrm{C}$ & p.(Arg943Pro) & $1^{c}$ \\
\hline 22 & c. $3059 \mathrm{~A}>\mathrm{T}$ & p.(Gln1020Leu) & $1^{\mathrm{a}}$ \\
\hline 22 & c. $3070 \mathrm{G}>\mathrm{A}$ & p.(Gly1024Arg) & $1^{c}$ \\
\hline 22 & c. $3071 \mathrm{G}>\mathrm{A}$ & p.(Gly1024Glu) & $2^{c}$ \\
\hline 23 & c. $3104 A>G$ & p.(His1035Arg) & $1^{j}$ \\
\hline 23 & c. $3105 C>G$ & p.(His1035GIn) & $1^{\mathrm{e}}$ \\
\hline 23 & c. $3109 \mathrm{G}>\mathrm{C}$ & p.(Asp1037His) & $2^{c, 1}$ \\
\hline 23 & c.3109G $>\mathrm{T}$ & p.(Asp1037Tyr) & $1^{\mathrm{c}}$ \\
\hline 23 & c. $3121 C>T$ & p.(Arg1041Trp) & $2^{b, d}$ \\
\hline 23 & c. $3122 \mathrm{G}>\mathrm{A}$ & p.(Arg1041GIn) & $3^{b, c, d}$ \\
\hline 23 & c. $3122 \mathrm{G}>\mathrm{C}$ & p.(Arg1041Pro) & $1^{k}$ \\
\hline 23 & c. $3125 A>G$ & p.(Asn1042Ser) & $1^{c}$ \\
\hline 23 & c. $3131 \mathrm{~T}>\mathrm{C}$ & p.(Leu1044Pro) & $1^{k}$ \\
\hline 23 & c. $3151 \mathrm{G}>\mathrm{A}$ & p.(Val1051Met) & $1^{\mathrm{c}}$ \\
\hline 23 & c. $3164 A>C$ & p.(Asp1055Ala) & $1^{c}$ \\
\hline 23 & c. $3164 A>T$ & p.(Asp1055Val) & $1^{p}$ \\
\hline 24 & c. $3257 \mathrm{~T}>\mathrm{C}$ & p.(Ile1086Thr) & $1^{e}$ \\
\hline 24 & c. $3316 \mathrm{G}>\mathrm{A}$ & p.(Glu1106Lys) & $1^{n}$ \\
\hline 24 & c.3323_3325delTCT & p.(Phe1108del) & $3^{c, d, e}$ \\
\hline 25 & c. $3341 \mathrm{C}>\mathrm{T}$ & p.(Pro1114Leu) & $1^{\mathrm{h}}$ \\
\hline 25 & c. $3344 A>G$ & p.(Tyr1115Cys) & $1^{\mathrm{c}}$ \\
\hline 25 & c. $3391 \mathrm{G}>\mathrm{C}$ & p.(Gly1131Arg) & $1^{\mathrm{c}}$ \\
\hline 25 & c. $3410 \mathrm{C}>\mathrm{T}$ & p.(Pro1137Leu) & $2^{d, f}$ \\
\hline
\end{tabular}


